\title{
Unreadable Poems and How They Mean Sherri Irvin
}

Please cite the published version, in The Philosophy of Poetry, ed. John Gibson (Oxford University Press, 2015), 88-110.

Several years ago, the poet and critic Joan Houlihan offered a scathing indictment of some contemporary poetry for using words in a way that treats them as meaningless. ${ }^{1}$ Of the words making up one offending poem, she asks, "Why are they printed in a journal someone paid to produce, for someone else to pay to read[,] instead of being spoken by a stroke victim in a rest home?"

She proposes, further, that the particular words of such poems are, in fact, inessential to them: massive substitutions can be made while preserving the poem's identity. She even goes so far as to transform a particular poem, Christina Mengert's “*."2 The original reads as follows:

Is an axle's excavation

an axiom's inversion

that muzzles

the ventriloquist breath

of a nipple. The revolving door

of its throat.

In revenge, Houlihan offers this:

Is an axiom's evacuation

an axle's inversion

that snubs

the ventriloquist bread

${ }^{1}$ Houlihan's series of nine essays, How Contemporary American Poets Are Denaturing the Poem, was published by Web del Sol from 2000-2005. All remarks quoted below are taken from Part VII (2003), "Post-Post Dementia,"

http://www.webdelsol.com/LITARTS/Boston Comment/bostonc7.htm, accessed most recently on September 28, 2011.

${ }^{2}$ Houlihan cites a version of the poem, titled with an asterisk, that appeared in issue 17 of Slope, winter/spring 2003. As Christina Mengert indicated to me in correspondence, it is an excerpt of a longer poem, "It Was, As They Say, A Threaded Body", that appeared in the second of six undated issues published by the online magazine Castragraf from 2000 to 2003. The full poem remains available here: http://www.castagraf.net/pdf/issue2.pdf. For the purposes of this essay, I will follow Houlihan in treating the Slope version as an independent work. 
of a testicle. The spinning jenny

of its lashes.

"I would argue my poem is the original," she says. "It is exactly the same poem, albeit with different words-but neither set of words makes any difference to the meaning."

We can reasonably take Houlihan's claim regarding the equivalence of the two poems as hyperbolic. There are serious questions here, though: can Mengert's poem, and other poems that use language in oblique, nonstandard, and ungrammatical ways, have actual meanings? Or are they susceptible only of a "chaotic democracy of 'readings'"3 imputed by readers who project idiosyncratic associations onto them? Moreover, if they can't have meanings, or if any meanings they do have are very difficult to access, does this undercut their value?

I will suggest that the meaning resources available to such seemingly unreadable poems are more extensive than Houlihan's charge might lead one to believe, and that one can gain access to them through practices of reading poetry that are already well established. At the end, I will offer a tentative apology for unreadability: the poems we are most likely to find unreadable are those that seem alien to us, and the appearance of alienness is often the product of gulfs of identity and experience that we have a duty to bridge.

Central to Houlihan's complaint is that it is impossible to tell what an unreadable poem is trying to do. There is, thus, no way of knowing what would constitute success, no way of knowing whether the substitution of a word would make the poem worse, improve it, or leave its quality untouched. ${ }^{4}$ This is why substitutions are acceptable: they don't make any difference to how well the poem achieves its (nonexistent) aims.

I agree that we evaluate artworks, in large part, based on an understanding of their aims. Following Stein Haugom Olsen, Peter Lamarque mentions the Principle of Functionality, a principle of reading according to which "what is there (in the poem)

\footnotetext{
3 E. D. Hirsch (1967), Validity in Interpretation (New Haven, CT: Yale University Press), p. 5.

4 "Since we don't know what original effect was intended, and since the only one we can experience directly is bafflement, we don't know how the line, or the poem for that matter, could be improved. What does improvement mean here? Or damage for that matter?" Houlihan, n.p. Emphasis in original.
} 
is there for a purpose[;] things are not just accidentally as they are." ${ }^{5}$ In reading, then, we attribute to the poem purposes or aims that allow us to make sense of its features. Some of these aims may be given by the art form, while others are particular to the work and are ascertained by inference from the work's features. Works of lyric poetry have, by virtue of belonging to that form, the aim of expressing the states of mind of the narrator. Particular lyric works have more specific aims: A. R. Ammons' poem "Mansion," for instance, aims to propose a vision of mortality. ${ }^{6}$ (This is a crude but, I hope, uncontroversial characterization of a central aim of the poem.) We know this straightforwardly, through its content:

So it came time for me to cede myself and I chose the wind to be delivered to

When the tree of my bones rises from the skin I said come and whirlwinding stroll my dust around the plain

We can ask, of Ammons' poem, how interesting and original is this vision? How rich and revelatory is it? How rewarding is the experience of immersing oneself in it?

What does Mengert's poem "*” supply by way of aim that can allow us to focus our assessments? Clearly, we will not be able to answer this question by reading off its manifest sentential content, in the way that we are able to do with "Mansion." For, as Houlihan observes, "*" may not have any sentential content. She reads the poem as beginning with a question, and that question is either aborted at the extra line break or ill punctuated: "Is an axle's excavation an axiom's inversion that muzzles the ventriloquist breath // of a nipple[?]" If this is a question, it is very difficult to know what is being asked (though one strongly suspects, nonetheless, that the answer is "no").

The situation is, in fact, even less clear than this. For there are at least two more ways of understanding the structure of the first sentence. First, it may be that the

5 Peter Lamarque (2009), "The Elusiveness of Poetic Meaning," Ratio 22: 398-420 at p. 412. Olsen's (1978) discussion occurs in The Structure of Literary Understanding (Cambridge: Cambridge University Press), at pp. 94-5.

${ }^{6}$ A. R. Ammons (1957), "Mansion," in Expressions of Sea Level (Columbus, OH: Ohio State University Press), p. 41. Below, I excerpt two of the poem's five stanzas. 
asterisk of the title serves as the sentence's grammatical subject. It is, after all, not unprecedented for the title to figure in the poem, to count as its beginning. The sentence may, then, be an assertion about the asterisk (* is an axle's excavation[,] an axiom's inversion[,] that muzzles the ventriloquist breath of a nipple.") rather than a question about an alleged equivalency between an axle's excavation and an axiom's inversion.

A further possibility is that titling the poem "*” is meant to position the body of the poem as some sort of footnote to another text which is not made available to the reader: the poem might, for instance, serve to elucidate some term in the unavailable text. This would make the opening sentence an assertion rather than a question, but with an unknown subject: “ is an axle's excavation...."

If these possibilities are all in play, we don't even know what the first sentence of the poem is; and even if we could select one of these options over the others, the meaning of the sentence would remain entirely unclear.

But then, the poem is telling us something, isn't it? "Don't look for my point or purpose in manifest sentential content." Of course it isn't in this poem's personality to say that so bluntly, but it seems very reasonable to see this as a message that emerges out of our thwarted attempts to read the poem in the standard way. The poem does invite us to make such attempts - it doesn't, after all, completely eschew grammar - but once we realize that our search for sentential meaning isn't working out, we know that we have to try something else.

We could give up, of course. If the poem wants to be so obnoxious in its tantalizing quasi-grammaticality and ultimate refusal of meaning, then we should treat it the way we would treat an obnoxious person: walk away (perhaps giving it a good scolding first, as Houlihan does).

I can understand the attraction of this response. In fact, as I was searching out poetic illustrations for this article, I often found myself caught in the introductions of books, fearful of venturing into the actual poems. I would flip back to the center of a book, read a few lines, and then balk. If I made it through a poem it was because the ending caught me by surprise. "What have I gotten myself into?" I thought. "Why did I choose a topic that would force me to consort with so many unfriendly poems?"

But it is also true that, since first seeing it reprinted in Houlihan's article several years ago, I have come to find "*” rather evocative. This is why I want to explore the meaning and function of such poems, as well as the duties we as readers might have to engage seriously with them.

So, back to the question of the poem's aim. The poem does not, as we have seen, have sentential content that will point us in the direction of its aim. Smaller units of content, below the sentential level, don't help much either: the pairings of "axle" and "excavation," of "axiom" and "inversion," perplex more than they inform. Is the axle 
being used to dig? Is it "excavating" the wheel into which it is inserted? And if so, what does this have to do with the inversion of an axiom (whatever that means), or with nipples or throats? We are not going to find the aim of the poem by first identifying some subject that the poem is about.

One option, here, is to revert back to an understanding of the aims of poetry more generally. Of course, one traditional aim of poetry is to convey a comprehensible meaning, and we already know that the poem has eschewed this aim. But there are other traditional aims that it seems to embrace. There is clear attention to meter and consonance (the repetition of the ' $x$ ' sound), especially in the first two lines, which have an intricate metrical structure that satisfies standard expectations about the rhythms of poetry. The metrical structure changes, and the consonance is dropped, when the poem reaches the line "that muzzles." This line, as we shall see, is a sort of fulcrum for the poem. The structure of sounds, then, has been carefully designed.

Houlihan's substituted poem fails to preserve many of these relationships. Her first two lines clearly lack balance, by comparison to Mengert's. Here are scans of the two poems using the ictus and $\mathrm{x}$ system, in which the ictus (slash) indicates a stressed syllable and the $\mathrm{x}$ an unstressed syllable:

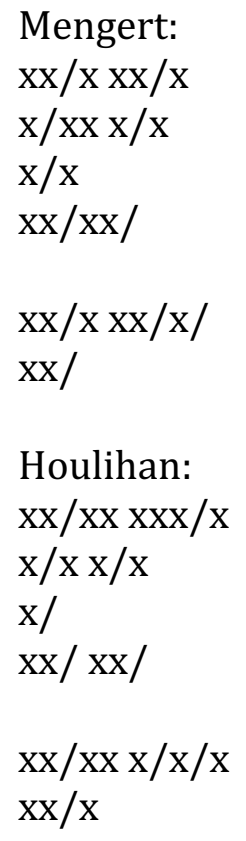

Houlihan:

$\mathrm{xx} / \mathrm{xx} \mathrm{xxx} / \mathrm{x}$

$\mathrm{x} / \mathrm{x} \mathrm{x} / \mathrm{x}$

$\mathrm{x} /$

$\mathrm{xx} / \mathrm{xx} /$

$\mathrm{xx} / \mathrm{xx} \mathrm{x} / \mathrm{x} / \mathrm{x}$

$\mathrm{xx} / \mathrm{x}$

Houlihan's first line has five unstressed syllables crammed in between the stressed syllables of "axiom" and "evacuation" respectively, but only two unstressed syllables between the two stressed syllables of the second line. As the result, on arriving at the end of the second line one has the feeling of being forced to pull up short after a sprint. Of course, there might be a poetic justification for this sort of effect. In any event, the rhythmic structure matters, and Houlihan's differs significantly from Mengert's. 
Another time-honored poetic aim is to activate the resonances and associations evoked by the poem's words, rather than merely their referential content. Mengert's poem appears to embrace this aim - indeed, to push it toward its outer limits, where resonances and associations replace referential content. It contains at least one obscure allusion: the line "The ventriloquist's breath" opens Lavinia Greenlaw's poem "Iron Lung,"7 published not long before Mengert's poem first appeared. If the ventriloquist breath is the breath induced by an iron lung, this brings new layers of resonance and possibilities of meaning to the poem: the axle's excavation now has a connection to the mechanistic action of the iron lung; the "revolving door of its throat" may be connected to the relentless forcing in and out of breath (although, of course, the throat of a breathing organism does not in fact function like a revolving door, allowing breath to enter and exit at the same time, so the association does not go through seamlessly).

The functioning of allusion is complex. Greenlaw's poem appears to be, at least in part, literally about the working of an iron lung: it begins, "The ventriloquist's breath / Watch while my lungs compress," and, later, mentions "A dark room I cannot go into / But am locked into from the neck". Mengert's use of an expression similar to Greenlaw's does not make it the case that Mengert's "ventriloquist breath" refers to breath induced by an iron lung. However, it does bring this association into play, lending the poem a weight of medicalization and mortality. ${ }^{8}$

With these observations in place, let me say something about the overall movement of the poem. It starts out tripping along with a clippy little meter, and using consonance (those x's) that is a little tongue-twisty. ${ }^{9}$ The first two lines have a very intellectual feel, inviting us to try to figure out what an axle's excavation and an axiom's inversion might be. And then, suddenly, it is muzzled. The muzzling shifts the rhythm of the poem, as well as its content. Each of the first two lines ends with an unstressed syllable, leaving things open for the rhythm to be picked up on the next line. But after the muzzling, each line ends with a stressed syllable, which creates, rather than a sense of continuity, a slight barrier that must be gotten over to arrive at the next line. (The first line after the extra line break - "of a nipple. The revolving door" - has the same structure of stressed and unstressed syllables as the first line of the poem, except that it adds a stressed syllable at the end.) The toetapping rhythm and cheery consonance are gone, replaced by something that is,

${ }^{7}$ Lavinia Greenlaw (1997), "Iron Lung," in A World Where News Travelled Slowly (London: Faber \& Faber).

${ }^{8}$ Peter Nicholls defends a similar view of allusion in "The Elusive Allusion: Poetry and Exegesis," in Teaching Modernist Poetry, ed. Nicky Marsh and Peter Middleton (New York: Palgrave Macmillan), pp. 10-24

9 This use of consonance, incidentally, is one of the things that tempts me to see the asterisk as a component of the poem: the 'sk' of asterisk twists the tongue in much the way that "axle's excavation" does, though the 'sk' sound is inverted into the 'ks' expressed by the letter ' $x$ '. 
suddenly, more corporeal than intellectual: the muzzled breath, the nipple (rising and falling, perhaps, with the breath), the throat. Both the content and the structure of the poem shift, at "muzzled," from being hard, mechanistic and intellectual to being organic and corporeal. We are confronted with soft, breathing body, instead of ideas and things placed in abstract relations. The perplexity we feel in the early lines of the poem, as we try to solve the puzzle of wordplay, morphs into a confusion that has more mystery and longevity to it as we contemplate these fragments of body. We no longer feel the promise that if we just think harder we will figure out what is meant. The poem becomes less about meaning and more about presence.

Interestingly, Houlihan's reading of the poem agrees with mine in significant respects. She says, "At its global level, the poem seems to posit the impersonal, nonhuman, mathematical, against/beside the human and personal." And she seems to agree that a shift occurs at "muzzles," though she disagrees about its significance: "Here's where some trouble begins," she says, suggesting that Mengert has constructed the rest of the poem through the technique of "finger-stabbing the best word in an open dictionary." A crucial element missing from Houlihan's reading, to my mind, is an appreciation of the relationship between the shift in semantic content and the shift in rhythm, and the way in which this relationship helps to justify the poet's specific word choices. As Patrick Suppes discusses, the rhythm of a poem has a direct effect on the reader, while also helping to activate associations and resonances of its semantic content. ${ }^{10}$ Lamarque, in a related vein, notes that the practice of reading poetry demands that we see form and content as unified, and that we seek an experience, not just a meaning, from the poem. ${ }^{11}$ Bearing these insights in mind, I find the interweaving of the rhythmic and semantic components of Mengert's poem to be one its most compelling aspects.

I see the poem, then, as inviting a certain kind of response to its early rhythmic and semantic elements, and then disrupting that response, suspending the reader in a corporeality that is not intellectually tractable. If this reading is apt, then it expresses the (or, at least, a) specific aim of this poem. I have arrived at an understanding of this aim by considering how the poem accommodates and rejects more standard aims of poetry having to do with reference, aural elements and associative meaning. With this notion of the poem's aim in hand, we seem to be able to think about how its various elements contribute to or undermine its achievement of its aim. We seem to be able to consider whether the substitution of a word would deepen the poem's pursuit of its aim or detract from it. The move from "muzzles" to "snubs," for instance, would undermine the sense of suffocation we have through the image of the muzzling of breath.

10 Patrick Suppes (2009), "Rhythm and Meaning in Poetry," Midwest Studies in

Philosophy 33: 159-166.

${ }^{11}$ Lamarque, "Elusiveness." 
I have spent quite a bit of time exploring various elements of the poem, and I haven't even given a very close reading of it: I haven't, for instance, said anything about how the potentially phallic image of the axle's excavation might relate to the bodily images in the final lines. I haven't considered a reading of the poem that takes the title "*” as the grammatical subject of its opening sentence, or that treats the poem as a footnote to some other text. I also haven't said anything about how this poem relates to the rest of Mengert's poem "It Was, As They Say, A Threaded Body" published in in Castagraf, ${ }^{12}$ whose parts tend to share the structure of four lines, an extra line break, and then two concluding lines. The full poem exhibits a recurring interest in anatomy, with passages such as "my ribs / deciphered and spread" and "Forgive my kamikaze / my ligaments." There is also another juxtaposition of intellect and body in this image:

Pedagogical/cranial

lunging of collision.

But is all of this worth doing? Is the energy I have spent here unpacking the poem, and the energy that could be spent unpacking it even further, worth spending? The work that was required to figure out what the poem might be up to is considerable, and the conclusion I arrived at is to some extent tentative and incomplete. But such work seems required in order to have a handle on the poem, to feel that one has a sense of what it is trying to do. An alternative approach to the poem would be to bask in it, allowing its sounds and images to wash over one, perhaps forming a sort of collage in the mind, and seeing how satisfying the resulting experience ends up being. That approach, for me, is only a starting point: once I have found the initial experience satisfying (or, in this case, enticing but perplexing), I want to delve deeper to see how the poem functions.

The "is it worth it" question, which I will take up again in the final section of this essay, seems related to these: Is my interpretation really just a projection? Could I come to just as satisfying an interpretation of a random string of words that might be put before me? Is there a multiplicity of other readings of this poem that are completely different from, even in conflict with, mine, yet equally well supported? If these questions are answered in the affirmative, this suggests that the meaning and value I attribute to the poem reside in me rather than in it. And if that is the case, I might as well dedicate my efforts to giving close readings of the texts that are included in some of my junk e-mail messages in an effort to elude spam filters: "Watch your years counted counterclockwise with us. TROL my feelings and to not express them. I had to control my feelings not only to try to get acceptance and to be able to fit in, but also had to control them in fear that if I Fire your main weapon!"

Is my interpretation of the poem a mere projection? Is there is a vast array of equally well supported readings? I will leave it to the reader to be the final arbiter of these matters. But I think it is fair to say that my interpretation appeals to straightforward features of the poem, such as its meter and sound structure and the

12 See note 2 . 
conventional meanings of its words. It doesn't appeal to the particularities of my own psychological response (although, as I've acknowledged, my motivation to interpret the poem was partly a function of my finding the initial exposure to it enticing - an experience that Houlihan clearly did not share). I take it that the claims I've made are subject to rational assessment: other readers can study the poem to see whether it is true, for instance, that both the structure and the semantic focus of the poem shift at "muzzled" as I've claimed, and whether the nature of those shifts is as I've described it. And, though this is a more subjective matter, they can consider whether the two shifts work together in a way that is satisfying and helps make sense of the poem.

If I've done my job as an interpreter, then, I've provided an explanation of the poem that is not random or purely subjective, but susceptible of intersubjective appraisal. This explanation includes an understanding of the poem's aim, and we can then use this understanding to see how well it achieves the aim through the specific resources it deploys. At first blush, this might sound circular: "After careful study, I conclude that the poem aims to do precisely what it is doing, and thus does it perfectly well!" But this is not quite right. The aim that is attributed in interpretation is sensitive to the particularities of the poem - it is not simply an aim that applies to poems in general - but it has to make sense of why these parts have been assembled in this way, not merely enumerate what the parts are and how they have been assembled. It has to operate at a higher level of abstraction than simply, "The poem does this, and then it does that, and finally it does the other thing; therefore, doing this, that, and the other thing is its aim."

This process of identifying the poem's aim(s) involves a feedback loop: I attribute a certain aim to the poem, but then I notice that my interpretation leaves out an important element or treats it as a flaw. I then attempt to identify another aim that makes sense of the poem roughly as well overall, while doing better by this other element. Eventually my explanatory efforts stabilize: either I am able to identify an aim that makes sense of all of the poem's elements and their interrelations, or I find that even my most charitable efforts lead me to attribute to the poem an aim on which it comes out to be flawed. The fact that interpretative efforts are charitable, and that they take the particularities of the poem seriously, does not guarantee the conclusion that the poem has satisfied its aim. Moreover, evaluation of the poem involves the further question of whether the aim pursued by the poem is worth pursuing. Even if the poem succeeds at its aim, the reader may conclude that that aim was trivial or bankrupt, and thus not such as to vindicate the poem.

For these reasons, we needn't worry that applying this interpretative method to random word sequences or strings of words embedded in junk e-mail messages will typically yield the verdict that these texts have literary value. We might, in some or many instances, be able to attribute an aim to such a text; but in most cases, the text will seem flawed even in relation to the aim we attribute to it after our most charitable efforts. Moreover, that aim itself will likely seem trivial or otherwise not worthy of our attention. 
Of course, there will be exceptions: even a random word generator will occasionally spit out a great poem. But it doesn't happen very often.

I have considered one example of a work that is singled out for excoriation by a critic. I have suggested, contrary to the critic's view, that it is in fact possible to attribute to the poem an aim that is appropriately responsive to its particularities (without objectionably guaranteeing its success) and that is intersubjectively verifiable. With this aim in hand, readers can then assess both (a) the extent to which the poem satisfies that aim and (b) whether that aim was worth pursuing in the first place.

I turn now to another target of Houlihan's ire, Gian Lombardo's “Partial Rhythm, Primate Laughing," ${ }^{13}$ which I present in its entirety:

Too soon drunk from mixed species. In this parasol no one gets out dead. Except for the passion. Wrung through and weepy. Shame on table pretending an animal belly up waiting.

Speaking under the influence of whatever the monkey sees does not seem true but just another corollary to arrest.

In this howl who calls?

Turning round on way up monkey takes a back.

My reading of this poem begins from a recognition of its many instances of wordplay: use of a linguistic expression that strongly evokes, through a visual and/or auditory resemblance mechanism, some other, more familiar expression. "Mixed species" evokes "mixed spirits," "corollary to arrest" evokes "coronary arrest," "monkey sees does" evokes "monkey see, monkey do," and "monkey takes a back" evokes "takes aback" as well as "monkey on my back." "No one gets out dead" is a reversal of the usual "no one gets out alive," and "speaking under the influence" recalls "driving under the influence."

These rather straightforward examples then open us, I think, to seeing other expressions in the poem as possible instances of wordplay: perhaps "parasol" should be thought of as evoking "parable," "pretending" as evoking "portending," and "wrung through" as evoking "rung through" (as when you call the front desk and they ring you through to a guest's room). "Shame on table" initially seems to treat shame (or a material symbol of it, or a person experiencing it) as having a

${ }^{13}$ Gian Lombardo (2003), Fence spring/summer issue. Reprinted in Lombardo (2004), Of All the Corners to Forget (New York: Meeting Eyes Bindery), p. 29. 
spatial location, but when we see the poem through the lens of pervasive wordplay we must consider it in relation to the formulation "shame on you." "In this howl who calls?" while alluding to Allen Ginsberg's famous poem, ${ }^{14}$ may also evoke an owl calling, "Who?"

What Lombardo is doing here, I think, is cracking open the conventional relations that words and expressions bear to linguistic meanings. It is nothing new for poetry to operate by activating associations, sometimes playing on the multiple senses of an ambiguous word and sometimes deploying the semantic content of a word that sounds or looks like a word that appears in the poem. But typically there is still a central, conventional meaning of the word or expression in the context of the poem, and this is the focal point for our reading: it is, we might say, what makes the poem readable. Even Mengert's poem, perplexing as it is, maintains this element of readability: we know what an axle is, and what excavation is, and though we may not be sure how these two concepts are supposed to fit together, the poem does not fundamentally destabilize or sever the relation between the words and their standard referential contents.

The pervasiveness of Lombardo's wordplay goes beyond the activation of associations: it also frays, though it does not completely sever, the connection between a word or expression and its main conventional meaning. "Too soon drunk from mixed species": a literal reading of "species" seems ruled out, since we can't make sense of what is meant by becoming drunk from mixed species, but we also can't read it as a malapropism for "spirits," since species fits in with the poem's mention of monkey, animal and primate. So we are suspended in a neither-nor of meanings: or perhaps in a neither-nor-both-and. Because Lombardo does this repeatedly, the effect seems pervasive, and even words like "pretending" and "parasol," which normally seem to have straightforward referential content, become destabilized. As Charles Bernstein puts it, the result is "[n]ot 'death' of the referent rather a recharged use of the multivalent referential vectors that any word has.... $[R]$ eference, deprived of its automatic reflex reaction of word/stimulus image/response[,] roams over the range of associations suggested by the word."15 This "recharging" of the reference potentiality of words, and the associated requirement that we read actively rather than just allowing our "automatic reflex reactions" to operate, is, in Bernstein's view, a central element of value in avantgarde poetry.

14 The allusion to a poem that is far longer than Lombardo's own work, and the comparison between the two that is achieved through the self-referential expression "this howl," raises fascinating issues that would need to be explored in a fuller analysis of Lombardo's poem.

15 Charles Bernstein (1984), "Semblance," in The $L=A=N=G=U=A=G=E$ Book, ed. Bruce Andrews and Charles Bernstein (Carbondale, IL: Southern Illinois University Press), p. 115. 
Lombardo's meaning play recalls strategies of abstraction in visual art that suggest representational content while also frustrating one's expectation that everything will come together and make sense. Kandinsky's Improvisation 7 (1910) works this way, in my view: it uses the palette of pastoral landscape, and some of its passages, through combinations of color and shape, evoke rolling hills, grasses, a grain elevator, a pond. The elements are not ultimately assembled so as to constitute a picture of something, but the feel of landscape nonetheless pervades the experience of the painting. Cy Twombly's works from the early 1960s, such as the Ferragosto series and Leda and the Swan, also come to mind: they are abstract patterns impregnated with phalluses, breasts, handprints, scrawled hearts, fecal smears. Twombly's works, like Kandinsky's, are not pictures of anything, but they do deploy the resemblance relations through which representation is established in pictures to bring in fragments of readable content that must color our understanding of the works. The visual stimulation of the Ferragosto works is pervaded by the muck and mess of bodies, by a sexual charge.

I see Lombardo's poem as employing both Twomblyesque and Kandinskyesque strategies. When he uses the word "parasol," which has clear, unambiguous referential content, he is drawing a little picture in the midst of his tableau, like one of Twombly's hearts in Leda and the Swan. (This does not prevent the parasol from triggering associations beyond its referential content, any more than the recognizability of one of Twombly's hearts prevents it from recalling breasts or buttocks.) And when Lombardo uses the words "Shame on table pretending an animal belly up waiting," he deploys the emotional palette of vulnerability, just as Kandinsky uses the palette of landscape. These maneuvers keep us tethered to content - the poem is very far from being pure sound - while also doing a lot to free words from the constraints of their literal senses.

This freeing up of words poses quite a challenge for the interpreter who tries to ascertain the meaning or message of the poem. When I assign student groups the task of interpreting the poem, the results diverge wildly. Some groups attempt to make sense of whatever literal content they can hold on to: the combination of drunkenness, shame, a belly, waiting and a table makes them think of unprotected sex, pregnancy, and a medical exam, so they put forward a literal interpretation incorporating these elements despite the fact that it is difficult to reconcile with the last three stanzas. Others see that this is unsatisfactory, and they try to relax into the feel of the poem and construct a more abstract interpretation that incorporates the emotional content and the juxtaposition of ideas about society (a parasol that traps us, killing our passion) and ideas about animality. Interpretations of the latter sort share some elements - they tend to bring into play themes of autonomy and emotional authenticity - but they do not converge; some groups, for instance, see the poem as having clear sexual content while others see the passion as emotional rather than sexual. There may not be anything in the poem that allows us to adjudicate among these readings with full confidence. 
Even an interpretation that attributes to the poem a sophisticated message about the human condition, though, seems ultimately unsatisfactory: for it doesn't take into account the fact that the poem refuses to be read as containing a clear message. Students often admit that the poem confused them, but they almost never incorporate this confusion into their interpretations. They seem to think that the goal of interpretation is to eliminate confusion, and that to the extent that they continue to feel confused it is a sign of their own incompetence. But the poem is so insistent on confusing us that an adequate interpretation must, it seems, present this as part of the poem's aim. If the poem is about the human condition as it relates uneasily to both sociality and animality, then it also presents or immerses us in (as opposed to merely describing) the confusion inherent in that condition. We are accustomed to making sense of things, to observing events and thinking that we understand what is happening; but the poem potentially forces us back into a state at which our easy fluency with cultural concepts and social conventions is undermined, and we see with fresh eyes just how baffling and inexplicable the events of our world really are.

To sum up, I see this poem as employing two strategies that are specifically related to its unreadability. First, it uses wordplay to loosen the connections between words an their conventional meanings, while also opening non-literal associative connections. This is, as I see it, a strategy of abstraction, along the lines used by Twombly and Kandinsky. Second, the poem acts on the reader, eliciting an experience of confusion rather than describing that confusion to convey its message. ${ }^{16}$ In this sense the poem functions a bit like a Zen koan whose aim is to force the meditator to transcend the constraints of analytic mind. ${ }^{17}$

An anonymous reviewer of this volume raises a worry about my approach, insofar as I aim to offer an aesthetic defense of "unreadable" poems:

Suppose ... the "meaning" of a very confusing poem is precisely to instantiate and enact confusion, as a means of representing the confusion that plagues modern humanity. That's plausible enough, in itself. But it's hard to see how a confusing poem could do anything, in terms of meaning, other than express confusion, or how an obscure poem could do anything other than enact obscurity, or how a poem that frustrates the reader's expectations could do anything other than embody frustration. And if those are the only meanings available to "unreadable poems," it is hard to see why people would bother to keep writing them, because those meanings have already been amply expressed.

I hope I have shown that Lombardo's poem does not simply express confusion or embody frustration. The poem's strategy of acting on us to produce confusion is

\footnotetext{
${ }^{16}$ Charles Bernstein suggests that criticism should ask of a poem "what it does" rather than "what it means." See Bernstein (2011), Attack of the Difficult Poems (Chicago: University of Chicago Press), p. 9.

${ }^{17}$ Houlihan remarks, though less favorably, on the koan-like aspect of some of the poems she discusses.
} 
interwoven with its other elements. Because it is made up of words and expressions in a natural language, it incorporates the meanings of those words and expressions, while also evoking other meanings that we associate with those words and expressions. Our confusion is not generalized and free-floating: it is confusion within a particular domain, in which we contemplate the human condition in relation to our conventional and animal natures. We are directed to this domain by devices such as the imagery of parasols and tables juxtaposed with laughing, climbing primates. Our confusion here is not identical to other confusions: it is populated by content and imagery the poem supplies. For this reason I'm not sure it's possible that a poem written in words could express confusion or enact obscurity or embody frustration without also bringing other meanings into play.

Lombardo has not, I have argued, put together random strings of words in a meaningless way. His words are not meaningless, but their relations to meaning are different than those in a conventional poem. And these unconventional meaning relations can plausibly be seen to serve the poem's central aim in a direct, experiential way. This is not to say that we must conclude that the poem is a great success. Some people hate Twombly, finding his scribblings pretentious or his exposure of the id distasteful. Much of one's evaluative response to Twombly's works depends on whether the visual experience of them is found to be interesting or pleasurable. I find Twombly's works far more satisfying than Lombardo's poem the specific abstract array of emotional color and partial semantic sense that Lombardo deploys just doesn't stimulate my interest as the best of Twombly's vigorous scrawl does; and I must admit that my tolerance for confusion and for the overthrow of analytic mind is limited. As Oren Izenberg says, "Estrangement is its own form of enchantment; difficulty can always be reconstituted as a subject matter of potential interest - and of pleasure - if that difficulty is to your taste." 18 Lombardo's variety of estrangement is not altogether to my taste. Nonetheless, I hold that an adequate approach to "Partial Rhythm, Primate Laughing" must see the poem as having comprehensible aims that are pursued by way of specific meaningrelated techniques.

Absent from my analysis so far is the relation of the author's intention to the meaning of the poem. A student once brought me a little slip of paper containing Gian Lombardo's e-mail address, in case I wished to contact him and find out what the poem is really about. ${ }^{19}$ The student, for whatever reason, chose not to do this dirty work.

${ }^{18}$ Oren Izenberg (2010), Being Numerous: Poetry and the Ground of Social Life (Princeton, NJ: Princeton University Press), p. 141.

${ }^{19}$ I've since had occasion to correspond with Gian Lombardo, who kindly supplied me with correspondence he had with Joan Houlihan following the publication of her article. In it, he writes, "If you ask me what the 'meaning' is, I'd have to reply that it is the poem. If I wanted to say it another way, I would have done so.... The poem states 
Should I have contacted Lombardo or Mengert? I have been tempted ask Mengert about the status of the asterisk as title; the fact that it was omitted when the complete poem was published online in Castagraf may be a clue that it doesn't have the importance attributed to it by some of the interpretative possibilities I raised earlier. (If the title is optional or incidental, then it shouldn't be seen as the grammatical subject of the poem's first sentence, for instance.)

When it comes to the interpretation of the works, though, I am not moved to consult the authors. I see authors as having the authority to fix their works' features: and it is through their actions of choosing the works' features, not through any other mechanism, that they determine the interpretation of the work. ${ }^{20} \mathrm{~A}$ poet, then, gets to decide which sequence of words will appear in the poem, and what the poem's title is, and what the spatial arrangement of the words will be. The poet also has the prerogative to incorporate aphorisms, subtitles, footnotes, or other textual elements. Gwendolyn Brooks often uses such strategies: the titles of several of her poems are followed by further lines of text, distinguished by indentation and style of type, that precede the main body of the poem. These lines sometimes provide a dedication, $a$ setting for the poem, or a quotation to introduce the text. "We Real Cool" 21 is introduced by such lines:

THE POOL PLAYERS. SEVEN AT THE GOLDEN SHOVEL.

We real cool. We

Left school. We

$\cdots$

Jazz June. We

die soon.

exactly what I wanted to say." In a message to me of July 27,2012 , he adds, "There is no 'correct' meaning other than itself." He favors a situation in which readers approach the poem by "inhabiting it \& making it theirs, as well as simultaneously 'understanding' it on its own terms."

${ }^{20}$ Sherri Irvin (2005), "The Artist's Sanction in Contemporary Art," Journal of Aesthetics and Art Criticism 63: 315-326.

21 Included in Brooks's collection The Bean Eaters (New York: Harper \& Brothers, Publishers, 1950), p. 17. The full text of the poem, along with a wonderful audio recording of Brooks reading and discussing the poem (and her dismay that it is the only one of her poems that many readers encounter), is available here: http://www.poets.org/viewmedia.php/prmMID/15433. 
The two opening lines provide the setting and positions a specific group of people as the speakers of the words in the body of the poem. Similarly, the poem "Bronzeville Woman in a Red Hat"22 is introduced by the lines

HIRES OUT TO

MRS. MILES

which allow the reader to grasp immediately that the early lines in the main body of the poem express the racist perspective of the white employer:

They had never had one in the house before.

The strangeness of it all. Like unleashing

A lion, really. Poised

To pounce. A puma. A panther. A black

Bear.

There it stood in the door,

Under a red hat that was rash, but refreshing -

In a tasteless way, of course - across the dull glare,

The semi-assault of that extraordinary blackness.

In each case, the opening lines directly constrain interpretation: a reading of "We Real Cool" that does not take into account the connection between the words and the pool players would be inadmissible, as would a reading of "Bronzeville Woman in a Red Hat" that fails to recognize that the dehumanizing 'it' is deployed in the mind of the white Mrs. Miles.

The poet thus has full authority to set the stage by determining the text and format of the poem, including the introductory lines. But things the poet might say in other contexts (interviews, journal entries, and so forth) about the poem's interpretation are, to my mind, suggestive without being decisive. They give us hints about where it might be sensible to look for the poem's themes and meanings, but it is up to us to determine whether the poem genuinely makes good on the poet's aspirations for it. ${ }^{23}$ Moreover, I wouldn't want to restrict the poem to having only meanings that the poet anticipated or has acknowledged. As Troy Jollimore remarks, "[M] etaphors, in a sense, transcend language by opening themselves up to aspects of the world that may not initially be embodied in the words themselves, and may perhaps even be unknown to the person who first deploys the metaphor in question."24

22 Included in The Bean Eaters, pp. 53-56.

${ }^{23}$ I discuss relevant arguments in Sherri Irvin (2006), "Authors, Intentions and Literary Meaning," Philosophy Compass 1: 114-128.

24 Troy Jollimore (2009), "Like a Picture or a Bump on the Head," Midwest Studies in Philosophy 33: 131-158, at p. 147. In relation to this insight Jollimore cites Richard Moran's (1989) "Seeing and Believing: Metaphor, Image, and Force," Critical Inquiry 16: 87-112 at p. 109. 
This is my view about interpretation generally, and I don't see that anything about unreadable poems mandates a different approach. Gian Lombardo might help us to see the importance of elements of his poem that we had overlooked, just as an especially perceptive reader might. But how the poem should be interpreted is ultimately a matter of whether those elements genuinely function as he wishes them to and believes they do. And I hope I have shown that we have non-negligible resources for assessing the workings even of poems that are strikingly unconventional in their grammar and word usage.

Appreciating an unreadable poem requires a willingness to consider it on its own terms, and to take seriously the possibility that it has a purpose that is defined by its idiosyncratic elements, including its refusal of conventional meaning. Reading in this way may lead us not to an articulable semantic meaning that we can attribute to the text, but instead to an experience that has semantic, rhythmic and non-cognitive elements. There is nothing particularly radical or surprising in this analysis: it deploys Olsen's (1978) Principle of Functionality as well as Lamarque's (2009) observation that the practice of reading poetry is such that we properly see poems as unities of form and content, with the result that the fruits of appreciation are experiences rather than meanings. Olsen's and Lamarque's theories are not tailored for difficult or avant-garde poetry; they are general theories about appreciation of literature and of poetry, respectively. We thus do not need to revolutionize our strategies to appreciate unreadable poems; we simply need to be willing to entertain a widening range of poetic purposes. I hope to have shown, through close examination of a couple of examples, how this can be done.

Some will remain unappeased by this analysis. Yes, it is possible, after long effort, to ascertain the aims of these tortured strings of words. But why not spend our time, instead, reading works that offer their rewards more freely, with less brain twisting? Or, to consider things from another perspective, is there any artistic justification for this mangling of language? Aren't there ample linguistic resources for describing and evoking a full range of experiences by using words and grammatical constructions in more customary ways?

T. S. Eliot offers one sort of answer to this question. "Our civilization," he writes, comprehends great variety and complexity, and this variety and complexity, playing upon a refined sensibility, must produce various and complex results. The poet must become more and more comprehensive, more allusive, in order to force, to dislocate if necessary, language into his meaning. ${ }^{25}$

25 T. S. Eliot (1975), “The Metaphysical Poets," in Selected Prose of T. S. Eliot, ed. Frank Kermode (London: Faber \& Faber), pp. 59-67, at p. 65. First published in the Times Literary Supplement, October 20, 1921. 
He concludes that "poets in our civilization ... must be difficult."26 This is an interesting proposal: there is something about the human condition in the industrial and post-industrial eras that demands an evolution of communication that outstrips the evolution of linguistic convention. If Eliot is right, then one supposes his point applies a fortiori to our own technologically saturated age.

There is another sort of justification for unreadable poetry that emerges not from a general observation about the nature of contemporary society, but from the situation of oppressed and subordinated groups. This justification has two facets. First, the situation of oppressed groups often demands coding and other modes of covert communication that are not accessible to the oppressors. As Louise Bennett discusses, when Africans in Jamaica were forbidden by the English to speak their original languages, they

disguise up de English Language ... in such a way dat we English forefahdersdem still couldn understand what we African ancestors-dem wasa talk bout when dem wasa talk to dem one annodder! ${ }^{27}$

As a result, "no so-so English-talkin smaddy cyaan understand weh we a seh if we doan want dem to understand weh we a seh, a oh!"28 The linguistic resources of a historically subordinated group, then, may be expressly designed to be unreadable by those outside the group. This highlights the important point that some unreadability is audience relative; a text may be unreadable by some while perfectly readable by others. Moreover, there may be no adequate replacement for words and expressions that are designed to be unreadable by the oppressors: they may have cultural resonance for members of the subordinated group that cannot be captured in any other way.

Second, insofar as the literary canon tends to be determined by the dominating group, the conventional linguistic resources that emerge out of that canon may be far better suited to describing the experiences of members of that dominating group. When members of a subordinated group attempt to capture their own experiences, they may feel a greater need for poetry that breaks open language in order to forge new semantic networks or to act directly on the reader to produce an experience rather than merely describing one. As Adrienne Rich describes, "[T]here is ... a difficult and dangerous walking on the ice, as we try to find language and images for a consciousness we are just coming into, and with little in the past to support us." 29 Women's experiences, Rich says, have been "wordless or negated" 30 under

\footnotetext{
26 Ibid., emphasis in original.

${ }^{27}$ Louise Bennett (1993), "Jamaica Language," in Bennett, Aunty Roachy Seh, ed. Mervyn Morris (Kingston, Jamaica: Sangster's Book Stores), p. 2.

28 Ibid.

${ }^{29}$ Adrienne Rich (1995), "When We Dead Awaken: Writing as Re-Vision," in On Lies, Secrets, and Silence: Selected Prose, 1966-1978 (New York: Norton), p. 35. An earlier version was published in 1972 in College English 34.

30 Rich, p. 34.
} 
patriarchy, their needs "misnam[ed] and thwart[ed]." ${ }^{31}$ If women are to find a way to express their particular experiences in this context, "nothing can be too sacred for the imagination to turn into its opposite or to call experimentally by another name. For writing is re-naming." 32 The sort of re-naming that is undertaken by members of subordinated groups may cause their poetry to seem gratuitously alien to readers steeped in the canon of the dominating group. But it is easy to see that this may be an ethical and political failing on the part of the audience, rather than a good reason to condemn the poetry.

Does the unreadability of Mengert's or Lombardo's poetry eventuate from their experience of the rapid evolution of contemporary culture, or from their positions as members of subordinated groups? It may stem from both of these to some degree, or from neither. There may be no way to know until we have looked carefully at their poems and immersed ourselves in the experiences they make possible. To dismiss such poetry out of frustration is to deny ourselves the occasion to develop interpretative skills that will serve us well in reading poems that have something crucial and incomparable to offer. ${ }^{33}$

\section{Bibliography}

Bennett, Louise (1993). “Jamaica Language.” In Bennett, Aunty Roachy Seh, ed. Mervyn Morris. (Kingston, Jamaica: Sangster's Book Stores), pp. 1-3.

Bernstein, Charles (1984). "Semblance." In The $L=A=N=G=U=A=G=E$ Book, ed. Bruce Andrews and Charles Bernstein (Carbondale, IL: Southern Illinois University Press), pp. 115-118.

(2011). Attack of the Difficult Poems (Chicago: University of Chicago Press).

Eliot, T. S. (1975). “The Metaphysical Poets.” In Selected Prose of T. S. Eliot, ed. Frank Kermode (London: Faber \& Faber), pp. 59-67

Hirsch, E. D. (1967). Validity in Interpretation (New Haven, CT: Yale University Press).

Houlihan, Joan (2003). “Post-Post Dementia." Web del Sol, http://www.webdelsol.com/LITARTS/Boston Comment/bostonc7.htm, accessed September 28, 2011.

31 Rich, p. 37.

32 Rich, p. 43.

33 I am grateful to Gian Lombardo, Amanda Silbernagel, Raz Spector, and an anonymous reviewer of this volume for helpful discussion and suggestions, to Gian Lombardo and Christina Mengert for permission to quote their poems, and to Gian Lombardo for permission to quote from correspondence. 
Irvin, Sherri (2005). "The Artist's Sanction in Contemporary Art." Journal of Aesthetics and Art Criticism 63: 315-326. 114-128. (2006). "Authors, Intentions and Literary Meaning." Philosophy Compass 1:

Izenberg, Oren (2010). Being Numerous: Poetry and the Ground of Social Life (Princeton, NJ: Princeton University Press).

Jollimore, Troy (2009). "Like a Picture or a Bump on the Head': Vision, Cognition, and the Language of Poetry." Midwest Studies in Philosophy 33: 131-158.

Lamarque, Peter (2009). “The Elusiveness of Poetic Meaning.” Ratio 22: 398-420.

Moran, Richard (1989). "Seeing and Believing: Metaphor, Image, and Force." Critical Inquiry 16: 87-112.

Nicholls, Peter (2010). “The Elusive Allusion: Poetry and Exegesis.” In Teaching Modernist Poetry, ed. Nicky Marsh and Peter Middleton (New York: Palgrave Macmillan), pp. 10-24.

Olsen, Stein Haugom (1978). The Structure of Literary Understanding (Cambridge: Cambridge University Press).

Rich, Adrienne (1979). "When We Dead Awaken: Writing as Re-Vision." In On Lies, Secrets, and Silence: Selected Prose, 1966-1978 (New York: Norton), pp. 33-49.

Suppes, Patrick (2009). "Rhythm and Meaning in Poetry." Midwest Studies in Philosophy 33: 159-166. 